\title{
O ENSINO DA ORALIDADE NO CURRÍCULO DO ESTADO DE SÃO PAULO
}

\author{
Gislene Aparecida da Silva Barbosa ${ }^{1}$, Bianca Prates Santana ${ }^{2}$, Thaís Matias Lima ${ }^{2}$ \\ ${ }^{1}$ Doutora em Educação pela Universidade Estadual Paulista - UNESP. Professora da Universidade do Oeste Paulista - \\ UNOESTE e Diretora Técnica do Núcleo Pedagógico da Diretoria de Ensino da Região de Presidente Prudente, \\ Presidente Prudente, SP. E-mail: barbosagislene@gmail.com \\ ${ }^{2}$ Graduanda em Letras pela Universidade do Oeste Paulista - UNOESTE.
}

\section{RESUMO}

Este artigo apresenta resultados de uma pesquisa de iniciação científica realizada em 2017 junto ao curso de Letras da FACLEPP, cujo objetivo foi investigar nos materiais didáticos de Ensino Médio "Caderno do Professor/Caderno do Aluno" de Língua Portuguesa (Secretaria Estadual de Educação de São Paulo) como é apresentado o ensino da oralidade, bem como que gêneros textuais orais secundários são enfatizados no processo de produção textual. Tendo como base o procedimento genebrino da Sequência Didática, foram analisadas: a justificativa social para a oralidade e para o gênero textual; a proposta de uma primeira produção do texto; a ampliação de repertórios de escuta de textos; a oferta de atividades de análise linguística, para sanar as dificuldades - permitindo a revisão; a solicitação de reelaboração do texto oral, garantindo, a circulação social do texto. A análise documental relevou que há escassez de gêneros orais secundários nos materiais e que as propostas de produção existentes, bem como as atividades com a oralidade, estão a serviço da escrita e não atendem às etapas de uma Sequência Didática que seja capaz de ensinar os estudantes a produzirem gêneros textuais orais.

Palavras-chave: Oralidade. Língua Portuguesa. Sequência Didática. Ensino. Aprendizagem.

\section{THE ORAL EDUCATION IN THE STATE OF SÃO PAULO CURRICULUM}

\begin{abstract}
This article presents results of a scientific initiation research held in 2017 next to the course of Letters of FACLEPP, whose objective was to investigate in the teaching materials of High School "Notebook of the Teacher/Notebook of the Student" of Portuguese Language (State Secretariat of Education of São Paulo) as the teaching of orality is presented, as secondary oral textual genres are emphasized in the process of textual production. Based on procedure of the Didactic Sequence, the following were analyzed: the social justification for orality and for the textual genre; the proposal for a first production of the text; the expansion of repertoires of listening texts; the provision of linguistic analysis activities to heal the difficulties - allowing for review; the request for reworking the oral text, guaranteeing the social circulation of the text. The documentary analysis revealed that there is a shortage of secondary oral genres in the materials and that the existing proposals of production and the activities with orality are in the service of writing and do not comply with the stages of a Didactic Sequence that is able to teach the students to produce oral textual genres.
\end{abstract}

Keywords: Orality. Portuguese language. Didactic Sequence. Teaching. Learning.

\section{INTRODUÇÃO}

Este artigo apresenta os resultados do projeto de iniciação científica "A presença da oralidade no ensino da Língua Portuguesa", o qual está vinculado ao curso de Letras/FACLEPP e investiga a qualidade dos materiais "Caderno do
Professor" e "Caderno do Aluno" de Língua Portuguesa do Ensino Médio (elaborados e distribuídos pela Secretaria de Educação do Estado de São Paulo), no que se refere à oferta e à sistematização de produções de texto oral. 
Grande parte dos materiais didáticos que circula nas escolas de Ensino Médio ampara-se em pesquisas linguísticas e educacionais que apontam a importância do trabalho com os diferentes gêneros textuais em sala de aula, para que os alunos possam, de fato, apropriarem-se dos gêneros orais e escritos que circulam socialmente e para que possam fazer uso dos mesmos nas distintas interações mediadas pela linguagem. Em outras palavras, valoriza-se um ensino embasado no letramento do aluno: proposta que acentua a ideia de que o acesso aos mais variados gêneros de texto, o estudo acerca das características comuns a estes gêneros e a relação íntima entre os textos e o uso social facilitam a construção de conceitos escolares e, consequentemente, formam leitores e escritores competentes e capazes de atuar significativamente nas esferas sociais (SOARES, 2004).

Nesse contexto a linguagem é entendida como forma ou processo de interação, ou seja, como uma atividade entre sujeitos (GERALDI, 2011). Esta concepção rompe com a ideia do monólogo, pois pressupõe o diálogo entre sujeitos que ocupam o espaço de interlocutores. Tampouco essa concepção prioriza apenas o código linguístico e suas regras, pois o enfoque está nos usuários da língua que interagem não só com base em regras linguísticas internalizadas, mas também inseridos em um contexto histórico e social. "O indivíduo, ao fazer uso da língua, não apenas exterioriza o seu pensamento, não somente transmite informações; na verdade, mais do que isso, realiza ações, age, atua, orientado por determinada finalidade, sobre o outro" (CURADO, 2004, p.19).

No processo de letramento, o estudante tem de aprender a interagir usando a linguagem, sob a forma de língua escrita e de língua oral, no entanto, parece haver na escola certa ênfase no ensino apenas da língua escrita, enquanto a oralidade costuma ficar de lado, como se pudesse ser aprendida espontaneamente. Contudo, Bakhtin (2003) destaca que os gêneros discursivos secundários são elaborações mais complexas construídas por certa esfera social, portanto seu domínio não costuma ocorrer em circunstâncias de uma comunicação verbal espontânea ou livre. Assim, podemos dizer que as entrevistas e os seminários, por exemplo, não são aprendidos em situações espontâneas como o que acontece na aprendizagem cotidiana do gênero conversa informal - que é um gênero primário.

Os gêneros discursivos secundários (complexos romances, dramas, pesquisas científicas de toda espécie, os grandes gêneros publicísticos etc.) surgem nas condições de um convívio cultural mais complexo e relativamente muito desenvolvido e organizado (...). No processo de sua formação eles incorporam e reelaboram diversos gêneros primários (simples), que se formaram nas condições da comunicação discursiva imediata. (BAKHTIN, 2003, p. 263).

Desde que o "Programa São Paulo faz escola" foi criado pela Secretaria Estadual de Educação de São Paulo (2007), materiais didáticos começaram a ser disponibilizados aos educadores das escolas estaduais. Nos anos de 2008 e 2009, teve início a distribuição, respectivamente, de "Cadernos do Professor" e "Cadernos do Aluno", nos quais constam situações de aprendizagem a serem desenvolvidas nas aulas das diferentes disciplinas. Atualmente, tais materiais estão organizados na edição vigente de 2014 a 2017 e organizam os conteúdos, temas e habilidades a serem trabalhados na escola de acordo com o Currículo do Estado de São Paulo (2012). Cerca de 5 mil escolas estaduais recebem esses materiais didáticos para o trabalho. No caso da disciplina de Língua Portuguesa, a ênfase do material está no desenvolvimento de leitura e de produção de texto a partir de gêneros textuais.

Os materiais "Caderno do Professor" e "Caderno do Aluno" vêm sendo construídos e caracterizados como um documento orientador do currículo para todas as escolas da rede estadual, sendo também por este motivo objeto de nossa pesquisa, para avaliar a eficácia das metodologias propostas para ampliação das capacidades de utilização da oralidade dos estudantes da escola básica, articulando a reflexão sobre os gêneros orais complexos em distintas situações de uso na sociedade (atividades de produção textual). 
Diante disso, o projeto de iniciação científica investigou os materiais "Caderno do Professor" e "Caderno do aluno" (visto que são complementares) de Língua Portuguesa das três séries do Ensino Médio (edição dos anos 20142017) no que se refere à presença da oralidade nas aulas de Língua Portuguesa, de acordo com as etapas de produção textual constantes no referencial teórico do procedimento Sequência Didática de autoria de pesquisadores da Universidade de Genebra: Dolz, Noverraz e Schneuwly (2004). Neste artigo, apresentamos como são organizadas as atividades de produção de texto oral e como a oralidade está presente no material, identificamos os gêneros orais priorizados, analisando a justificativa social para a oralidade, a proposta de elaboração de uma versão inicial do texto, tendo em vista o levantamento dos saberes do aluno, a ampliação de repertórios de escuta de textos orais, a oferta de atividades de análise linguística e a solicitação de reelaboração do texto oral. Este texto está organizado em: apresentação da metodologia, discussão dos resultados e considerações finais.

\section{METODOLOGIA}

A opção pela análise documental deve-se à necessidade de, em primeiro lugar, analisar a qualidade dos materiais que circulam na escola pública com pretenso objetivo de subsidiar as ações docentes no ensino de Língua Portuguesa; em segundo lugar, de confrontar tais materiais aos estudos linguísticos e metodológicos contemporâneos, no intuito de encontrar ou não unanimidade de conceitos e considerações sobre o ensino e a aprendizagem da oralidade na escola atual e; em terceiro lugar, ser um referencial bibliográfico para o meio acadêmico e para pessoas interessadas no assunto tratado na pesquisa.

Pela análise documental, de natureza qualitativa, a fonte primária da coleta de dados (MARCONI; LAKATOS, 2003) foi os materiais de 1a série a 3a série (Ensino Médio) do Programa São Paulo faz Escola que distribui às escolas o "Caderno do Aluno" e "Caderno do Professor" (Língua Portuguesa - edição 2014-2017), os quais estão divididos em dois volumes (para cada série) e trazem atividades para ensino de leitura, produção de texto e análise linguística. Neste artigo (e também na pesquisa de iniciação científica) interessa-nos a análise da produção textual oral, tendo como base os referenciais teóricos que discorrem sobre a Sequência Didática.

O método de análise do material consiste em leitura criteriosa, amparada pelos referenciais teóricos, a partir da qual cada etapa de sistematização da produção textual de oralidade é analisada, comparando o que os autores genebrinos propõem para a construção de uma Sequência Didática e o que os materiais em análise apresentam. Portanto, trata-se de localizar todas as atividades de produção textual, levantando quais delas propõem o trabalho com gêneros orais; identificar os gêneros orais constantes nos materiais e a justificativa social para a inserção deles; analisar a presença das etapas de produção textual à luz da Sequência Didática e de demais teorias relacionadas aos gêneros textuais orais e ao ensino da Língua Portuguesa; registrar a análise em tabelas e textos acadêmicos de caráter reflexivo, apontando as potencialidades e as fragilidades dos materiais em análise quanto ao trabalho com a oralidade.

Neste sentido, é essencial apresentar o conceito de Sequência Didática, o qual organiza o procedimento de análise dos materiais didáticos mencionados neste artigo. Assim, a Sequência Didática tem a finalidade de ajudar o aluno a dominar melhor um gênero de texto, permitindoIhe, assim, escrever, ler ou falar de uma maneira mais adequada numa dada situação comunicativa. Ela decompõe as atividades comunicativas complexas, que os estudantes ainda não são capazes de produzir sozinhos, para que possam estudar, um a um, os componentes que se mostrarem como obstáculos à aprendizagem e à realização do gênero de texto. Funciona como instrumento de orientação ao trabalho docente, sistematizando o ensino.

Dolz, Noverraz e Schneuwly (2004, p. 98) desenvolveram um esquema para representar as etapas que compõem uma Sequência Didática: apresentação da situação; produção inicial; módulos; produção final, conforme a figura a seguir: 
Figura 1. Esquema da Sequência Didática genebrina

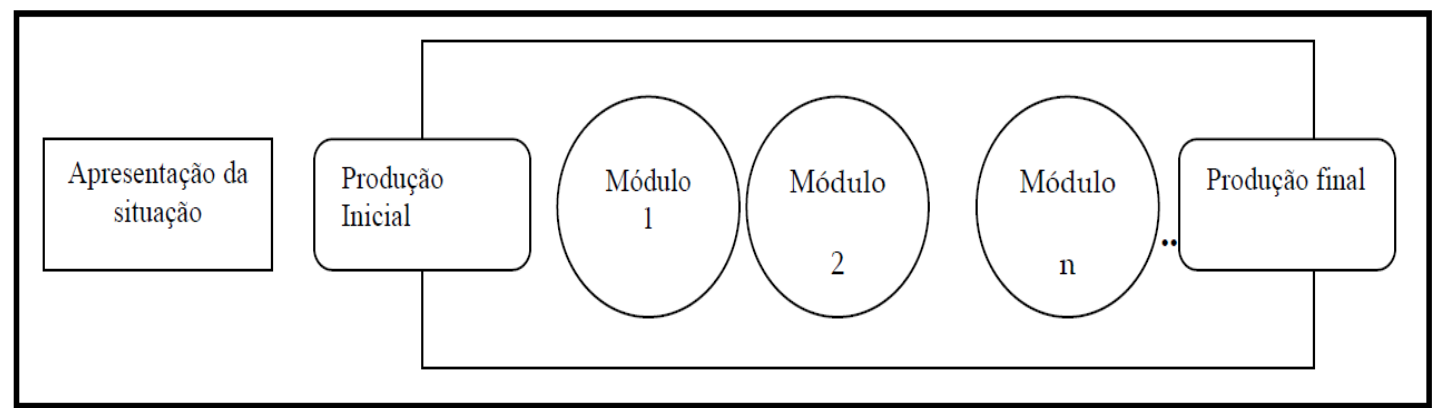

Fonte: Dolz, Noverraz e Schneuwly (2004, p. 98).

A apresentação da situação é a etapa de expor "aos alunos um projeto de comunicação que será realizado verdadeiramente na produção final" (p. 99). Essa etapa requer, ainda, a apresentação de "um problema de comunicação bem definido" (p. 99) e a preparação dos "conteúdos dos textos que serão produzidos" ( $p$. 100). Respectivamente, é necessário definir o gênero textual oral a ser trabalhado, o destinatário, a forma que a produção assumirá (vídeo, áudio etc.), quem participará do projeto; depois é necessário que os alunos saibam com quais conteúdos vão trabalhar e a importância desses conteúdos no texto em produção.

A etapa produção inicial é o momento de os alunos colocarem em evidência, para si mesmos e para o professor, o que sabem sobre o gênero selecionado para estudo. Na produção inicial, nos dizeres dos autores mencionados, o docente tem a oportunidade de "realização prática de uma avaliação formativa" (p. 102), porque a produção de texto evidenciará o que cada estudante sabe.

Na etapa módulos, o professor trabalha, separadamente, com os problemas que apareceram na primeira produção, ou seja, decompõe o gênero textual oral para abordar problemas de níveis diferentes, tais como a representação da situação comunicativa (a fim de focalizar o destinatário, ter clareza da finalidade da produção textual, saber seu papel como interlocutor e saber a função que o gênero textual selecionado exerce socialmente); a elaboração dos conteúdos (buscar, elaborar ou criar conteúdos de acordo com a especificidade de cada gênero); o planejamento do texto (manter certa padronização da estrutura composicional do texto em foco); a realização do texto (escolher o vocabulário adequado, usar bem os verbos, trabalhar com os argumentos etc.).

A última etapa é a produção final, a qual oportuniza ao aluno colocar em prática o que aprendeu ao longo dos módulos, ter consciência de seu próprio processo de aprendizagem e trabalhar como regulador de seu próprio comportamento na revisão e reescrita do texto que circulará socialmente.

A produção final também serve como avaliação somativa para uso do professor, o qual pode corrigir o texto com o apoio de uma grade que expõe os elementos necessários ao desenvolvimento do gênero textual, os critérios de correção e a nota atribuída a cada item. Com a grade, o docente tem uma visão sistemática das aprendizagens dos alunos; assim, fica mais acessível ao educador a retomada de itens não apreendidos pelos estudantes.

A grade permite-lhe
centrar sua intervenção
em pontos essenciais,
supostamente aprendidos
pelos alunos ao longo da
sequência. Assim, a grade
serve, portanto, não só
para avaliar num sentido
estrito, mas também para
observar as aprendizagens
efetuadas e planejar a
continuação do trabalho,
permitindo retornos a
pontos mal assimilados.
(DOLZ; NOVERRAZ;
SCHNEUWLY, 2004, p.
107).

Diante das etapas expostas, é possível perceber que a Sequência Didática é uma oportunidade de sistematizar o ensino da oralidade, portanto ela tende a acrescentar muito 
na qualidade formativa dos alunos, pois é didaticamente organizada para fazer o estudante pensar em cada etapa de elaboração de um gênero oral, reconhecendo a situação comunicativa; a forma, o estilo e o conteúdo do texto em construção; estudando aspectos linguísticos e extralinguísticos que colaboram na construção textual.

\section{DISCUSSÃO E RESULTADOS}

Os gêneros orais secundários não são aprendidos de maneira espontânea no cotidiano. Diferente da conversa informal, que é um gênero oral primário, pois esta não necessita de aprendizado escolar/sistematizado, o gênero oral secundário requer instrução para ser aprendido, é o caso das entrevistas, das palestras e dos seminários.

Quando o sujeito atua no mundo e precisa valer-se de um gênero oral para mostrar suas opiniões (em um debate, por exemplo), tem de colocar em prática tudo o que sabe sobre o gênero e recorrer aos conhecimentos construídos por meio da intervenção das aulas de Língua Portuguesa. Se a formação linguística do aluno não contemplar o desenvolvimento da oralidade, suas chances de atuar socialmente com sucesso tendem a reduzir, porque são comuns situações nas quais a oralidade é requerida: entrevista de emprego, seminários na vida de estudante, palestras na área profissional etc. Quanto mais possibilidades de elaboração de gêneros orais secundários o estudante da escola básica tiver, maiores serão as possibilidades de formação de cidadãos autônomos, capazes de agirem com a escrita e com a oralidade, nas mais distintas situações cotidianas de leitura e de produção textual. Assim o estudante poderá ter uma consciente participação social, uma possibilidade de prosseguimento dos estudos e o acesso ao mercado de trabalho, atendendo ao princípio democrático apresentado na Lei de Diretrizes e Bases da Educação Nacional.

Um dos objetivos propostos na pesquisa é identificar a justificativa social para a oralidade, a definição de um projeto comunicativo e de um gênero textual, ou seja, se o material era relevante ao apresentar o motivo de se escolher um gênero oral e qual sua função social: como se manifesta nos materiais a etapa da apresentação da situação.

A apresentação da situação é o momento de primeiro contato dos alunos com o gênero oral. Professor e estudantes definirão um projeto de comunicação que será concretizado na produção final. Tal projeto inclui o levantamento de um problema de comunicação e a escolha de conteúdos para as produções.

Apresentação da situação
é, portanto, o momento
em que a turma constrói
uma representação da
situação de comunicação e
da atividade de linguagem
a ser executada. Trata-se
de um momento crucial e
difícil no qual duas
dimensões principais
podem ser distinguidas: a)
apresentar um problema
de comunicação bem
definido; b) preparar os
conteúdos dos textos que
serão produzidos. (DOLZ;
NOVERRAZ; SCHNEUWLY,
2004, p. 99-100).

O material da terceira série do Ensino Médio solicita aos alunos que preparem seminários para compartilhar resultados de uma pesquisa de tarefa de casa, por exemplo. Contudo, não há referência ao valor social do seminário, tampouco são apresentadas suas características essenciais ou oferecidos roteiros que ajudem os estudantes a compreenderem como se organiza a fala na forma, no estilo e no conteúdo propostos para a atividade escolar. Significa dizer que o material pede que os alunos elaborem seminários sem considerar que o gênero textual oral deva ser ensinado, como se todos os educandos já soubessem elaborar o texto oral.

Dessa forma, não há no "Caderno do Professor" e no "Caderno do Aluno" a preparação para a turma compreender o que deva ser elaborado na oralidade. Numa perspectiva bakhtiniana, todo gênero discursivo é organizado em enunciados que estabilizam formas e rotinas das práticas linguageiras, portanto a tomada de consciência desses aspectos pelos interlocutores é essencial para favorecer a produção eficiente do texto. Para os autores genebrinos, tornar claros os conteúdos, as estruturas e os usos das unidades de linguagem que compõem um gênero de texto torna-se o ponto de partida para ensinar o domínio de produção textual:

Para definir um gênero como suporte de uma atividade de linguagem três dimensões parecem 


\begin{abstract}
essenciais: 1) os conteúdos e os conhecimentos que se tornam dizíveis por meio dele; 2) os elementos das estruturas comunicativas e semióticas partilhadas pelos textos reconhecidos como pertencentes ao gênero; 3) as configurações específicas de unidades de linguagem, traços, principalmente, da posição enunciativa do enunciador e dos conjuntos particulares de sequências textuais e de tipos de discursos que formam sua estrutura. 0 gênero, assim definido, atravessa a heterogeneidade das práticas de linguagem e faz emergir toda uma série de regularidades no uso. (DOLZ; SCHNEUWLY, 2004, p. 75).
\end{abstract}

O segundo objetivo é analisar se há proposta de elaboração de uma versão inicial de texto, com vistas ao levantamento dos saberes dos alunos e à avaliação inicial do professor para identificar as dificuldades deles. Após a definição do problema e a preparação dos conteúdos, começa a etapa da primeira produção, na qual "os alunos tentam elaborar um primeiro texto oral ou escrito e, assim, revelam para si mesmos e para o professor as representações que têm dessa atividade" (DOLZ; NOVERRAZ; SCHNEUWLY, 2004, p. 101).

Contudo, nos materiais em análise, as atividades propostas de elaboração de um gênero oral secundário são feitas sem dar margem ao aluno para conhecer o gênero em questão. $O$ professor, ao qual caberia investigar 0 que os alunos sabem sobre o gênero para depois fazer as intervenções necessárias, não tem incentivo do "Caderno do Aluno/Professor" para tal investigação. Podemos notar este resultado com base na Situação de Aprendizagem 3: Você está na mídia? do "Caderno do Professor" da 1a série - volume 1 (p. 25), na qual aparece uma proposta de uma realização de uma entrevista sem antes o docente levantar os saberes da turma em relação a esse gênero proposto. $\mathrm{Na}$ referida atividade, o material solicita ao aluno uma pequena entrevista com seus pais, irmãos ou vizinhos para identificar o que pensam sobre a importância da televisão na vida deles. Os alunos podem usar algumas perguntas discutidas em sala de aula: "Qual a importância da televisão em sua família? E em sua vida pessoal?; Em sua opinião, televisão "emburrece"?" (p. 26). Assim, a atividade pressupõe que o aluno conheça o gênero oral secundário entrevista, por isso a orientação para a lição de casa não apresenta as características do gênero escolhido.

Privar os estudantes de realizar uma sondagem de seus saberes (para com base nos resultados da produção inicial o docente intervir na aprendizagem) pode levar as atividades de análise linguística a um estudo descontextualizado, porque aprender a língua pressupõe reflexão a partir dos usos feitos pelos estudantes em seus textos (GERALDI, 2011). Nos dizeres dos autores genebrinos, garantir a etapa da produção inicial favorece a aprendizagem de elaboração textual e dá sentido à prática de criação de textos na escola:

A produção inicial tem um papel central como reguladora da sequência didática, tanto para os alunos quanto para o professor. Para os alunos, a realização de um texto oral ou escrito concretiza os elementos dados na apresentação da situação e esclarece, portanto, quanto ao gênero abordado na sequência didática. Ao mesmo tempo, isso Ihes permite descobrir o que já sabem fazer e conscientizar-se dos problemas que eles mesmos, ou outros alunos, encontram. Por meio da produção, o objeto da sequência didática delineia-se melhor nas suas dimensões comunicativas e também se manifesta como lugar de aprendizagem necessária das dimensões problemáticas. Assim, a sequência começa pela definição do que é preciso trabalhar a fim de desenvolver as capacidades de linguagem 


\begin{abstract}
dos alunos que, apropriando-se dos instrumentos de linguagem próprios ao gênero, estarão mais preparados para realizar a produção final. (DOLZ; NOVERRAZ; SCHNEUWLY, 2004, p. 102).
\end{abstract}

O terceiro objetivo é investigar se existe a ampliação de repertórios de escuta de textos orais, pois para que o gênero oral seja aprendido é necessário ampliar os conhecimentos prévios dos alunos, oferecendo-lhes a escuta de entrevistas, seminários, palestras etc. com o objetivo de pensar sobre a construção desses gêneros textuais orais. Uma das maneiras de proporcionar tal expansão de saberes é pela indicação de vídeos e áudios disponíveis na internet que possam ser acessados por alunos e professores. Porém, essa indicação de escuta não foi encontrada nos materiais, nem nas sugestões de atividades complementares no "Caderno do Professor".

Analisando os dois volumes de materiais de cada série do Ensino Médio, deparamo-nos com a oferta de 194 atividades que solicitam aos alunos e ao professor uma conversa ou debate sobre algum tema, assim vemos que a oralidade é presente em quase todas as situações de aprendizagem (capítulos que organizam um conjunto de aulas a partir de um tema/habilidade), contudo em 62 vezes a conversa solicitada nas atividades servirão para a elaboração escrita de um texto e em apenas 13 atividades serão utilizados gêneros orais secundários como recursos para tematizar um assunto fruto de pesquisa, tarefa de casa ou preparação para redigir texto dissertativo, conforme expomos no gráfico a seguir:

Gráfico 1. Atividades de produção escrita e produção oral encontradas nos materiais de Língua Portuguesa - Ensino Médio

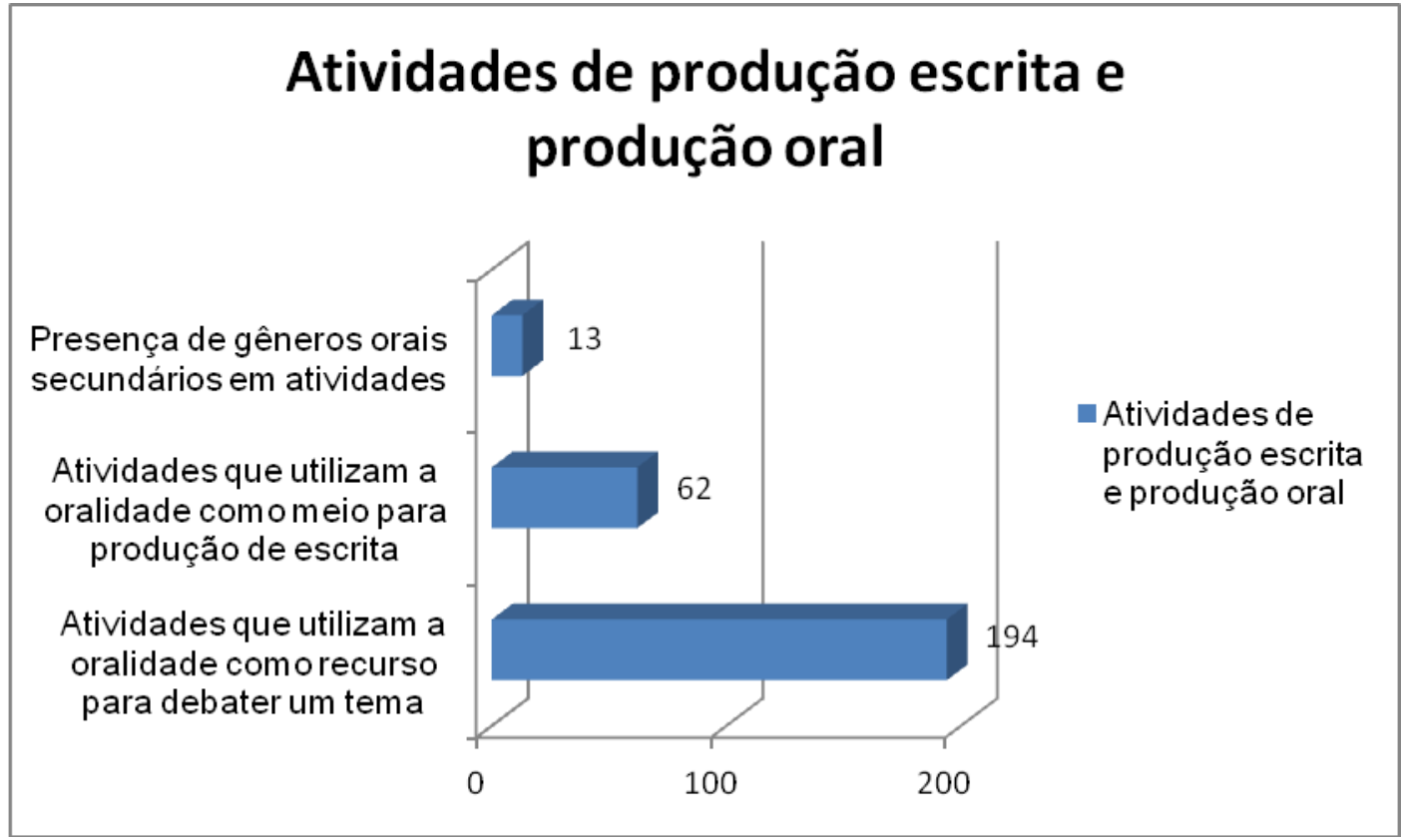

Fonte: As Autoras (2017).

Com o gráfico vemos que os gêneros orais secundários não são priorizados pelo sistema de ensino, já que há diferença entre conversar sobre um assunto (estruturalmente, a conversa em sala de aula carrega aspectos de informalidade) e elaborar intencionalmente gêneros orais secundários a partir de reflexões sobre a função social, a forma, o conteúdo e o estilo linguístico de tais textos. Não identificamos atividade que proporciona reflexão acerca de como se constituem os textos orais.

As conversas informais estão presentes nos materiais das três séries, porém existem para subsidiar a construção de gêneros textuais escritos. No "Caderno do Aluno", volume 2 da 1a série, durante a Situação de Aprendizagem 6: 0 estilo que critica o mundo (p. 59), é possível entendermos que a informalidade da oralidade está entrelaçada com a criação de gêneros 
textuais. Na atividade de Lição de Casa (p. 64) é solicitada uma discussão oral sobre como a literatura pode refletir a sociedade, em seguida, os alunos devem criar um estilo literário e, como projeto final, um texto escrito.

Outro exemplo está no "Caderno do Aluno", na Situação de Aprendizagem 1: Rindo se criticam os costumes! - volume 1 da $2^{a}$ série (p. 5), na qual encontramos um momento de discussão oral (p. 9). Os alunos são instigados a discutirem algumas questões, como: "O tema do abuso do poder presente em $\mathrm{O}$ juiz de paz da roça ainda é atual? Por quê?; Que exemplos de sua comunidade você consegue relacionar com o texto lido? Por quê?". Estas questões foram elaboradas com o intuito de se produzir um desfecho para o texto teatral lido anteriormente.

Os exemplos de uso informal de oralidade encontram-se dispostos nos volumes de todas as séries. Por exemplo, na Situação de Aprendizagem 5: Planejando a felicidade (p. 40) volume 2, "Caderno do Aluno", 3a série - os jovens devem discutir em sala de aula várias questões relacionadas ao futuro: "Você consegue imaginar sua vida daqui a um ano? $O$ seu futuro influencia o futuro de outras pessoas? Como?", estas perguntas servirão de base para a produção de um texto escrito a respeito de escolhas como o vestibular. Desta forma, a oralidade existe apenas como fator secundário dentro do material.

O quarto aspecto investigado é a presença de atividades de análise linguística para sanar as dificuldades dos alunos no que se refere ao conhecimento semântico, morfossintático, fonológico, textual, pragmático que interferem na elaboração de textos orais. Tanto o terceiro quanto $\mathrm{o}$ quarto aspectos investigados na pesquisa estão relacionados à etapa dos módulos da Sequência Didática. É durante os módulos que o docente vê ampliada sua oportunidade de intervir sobre a aprendizagem da turma de alunos, pois trabalhar a partir das necessidades reais dos estudantes, utilizando o que eles já sabem para que, com ajuda, alcancem o que ainda não dominam é um processo essencial na escola. No caso, cada atividade de reflexão sobre a língua ajudará o aluno a melhorar sua produção final, ampliando passo a passo o que conhece, a fim de que aprenda a produzir textos orais:

O movimento geral da sequência didática vai, portanto, do complexo para o simples: da produção inicial aos módulos, cada um trabalhando uma ou outra capacidade necessária ao domínio de um gênero. No fim, o movimento leva novamente ao complexo: a produção final. (DOLZ; NOVERRAZ; SCHNEUWLY, 2004, p. 103).

De acordo com Gatinho (2006), garantir atividades reflexivas sobre os aspectos linguísticos e ofertar a ampliação de repertórios do texto em pauta colabora na expansão das práticas de produção textual dos alunos:

Do ponto de vista didático, nessa forma de modelização reside a crença de que a sequência de atividades didáticas serve para direcionar as atividades com e sobre a língua e, dessa forma, dar aos alunos acesso a novas práticas de linguagem. Assim, as atividades de leitura e análise linguística nela construídas funcionariam como andaimes para a prática de produção de textos. Aqui também há o pressuposto de que quanto maior a articulação ou alinhamento entre as atividades de leitura, análise linguística e produção de textos tanto melhor poderá ser o desempenho do aluno nas práticas sociais de uso da linguagem. (GATINHO, 2006, p. 148).

Nos materiais, não encontramos tais atividades a serviço da construção de gêneros orais secundários. As atividades de análise linguística que servem para melhorar vocabulário, concordância e coerência, além de outros elementos linguísticos, aparecem apenas relacionadas à produção escrita. Como exemplo, citamos a Situação de Aprendizagem 1: Me corrijam se eu estiver errando... (p. 5) - volume 1 , "Caderno do Aluno" da 3 a série, na qual há destaque para questões ortográficas vinculadas à 
elaboração de um bilhete, conforme destacamos

no quadro a seguir:

Quadro 1. Análise linguística nos materiais de Ensino Médio

\begin{tabular}{|c|c|}
\hline $\begin{array}{c}\text { Exemplo de atividade - "Caderno do Aluno" da 3a } \\
\text { série - volume } 1 \text { (p. 6) }\end{array}$ & Análise da a \\
\hline $\begin{array}{l}\text { De acordo com a norma padrão da língua } \\
\text { portuguesa, complete as seguintes palavras } \\
\text { com: } \\
\text { a) G ou J: pa_é, enri_ecer, laran_a, } \\
\text { pa_em, can_ica, tra_e, refú_io. } \\
\text { b) S ou Z: cremo_o, pobre_a, burguês, } \\
\text { cin_eiro, cafe_al, vaido_o, trombo_e. } \\
\text { Por que escrevemos com letras diferentes } \\
\text { palavras que são pronunciadas com os } \\
\text { mesmos sons?[...] } \\
\text { Que regra gramatical explica o uso de z nas } \\
\text { palavras: beleza, tristeza, madureza, } \\
\text { fraqueza e esperteza? }\end{array}$ & $\begin{array}{l}\text { A atividade ressalta a análise linguística apenas a } \\
\text { serviço da produção escrita. Em sala de aula, os } \\
\text { alunos devem reescrever um bilhete proposto } \\
\text { levando em consideração adequação } \\
\text { ortográfica, concordância, numerais, } \\
\text { formalidade e eco. } \\
\text { Este tipo de atividade proposta seria } \\
\text { significativo se aplicado em um texto oral, para } \\
\text { perceber adequações e inadequações na fala, } \\
\text { como se articulam os sons e como estes } \\
\text { influenciam a vida pessoal, social e profissional, } \\
\text { portanto caberiam atividades de fonética e } \\
\text { fonologia, no entanto elas não existem no } \\
\text { material. }\end{array}$ \\
\hline
\end{tabular}

Fonte: As Autoras (2017).

Por último, analisamos se há nos materiais a solicitação de reelaboração do texto oral, garantindo a circulação social do texto e a oportunidade de o aluno colocar em prática a revisão textual, melhorando a primeira produção e construindo um texto oral (produção final) que cumpra sua função e atenda às características inerentes ao gênero oral em foco. $O$ que encontramos foi somente atividade de produção oral que não permite a reelaboração do texto.
No "Caderno do Professor" da 3a série, volume 2, na Situação de Aprendizagem 4: África e Brasil...Isso dá Literatura (p. 31) nos deparamos com uma proposta de atividade de um gênero oral secundário: seminário. No entanto, essa atividade não visa à reelaboração do texto, já que o foco não é aprender o gênero textual seminário, mas sim conhecimentos de literatura que serão debatidos na aula, conforme apresentamos no quadro a seguir:

Quadro 2. Reelaboração de texto oral nos materiais de Ensino Médio

Exemplo de atividade - "Caderno do Professor" Análise da atividade

da 3 a série - volume 2 (p. 38)

Peça aos alunos que se organizem em duplas ou em trios. Cada dupla/trio procurará um texto (ou um trecho) literário de um autor moderno da literatura brasileira ou de um país africano de língua portuguesa que estabeleça um diálogo com os Textos

1, 2 e 3, escolhidos de autores brasileiros do século XIX [...].

Professor, após a realização da pesquisa, eles farão um seminário, que objetiva a aprendizagem da classe com os conhecimentos adquiridos pelos colegas; será também uma ótima oportunidade para adquirir experiência de falar em público em um registro mais formal.
Ao propor um seminário como forma de apresentação de uma pesquisa é de se esperar que os alunos já tenham sido expostos a esse gênero oral em um momento anterior. No entanto, isso não fez parte de outra atividade, portanto concluímos que não se enfatiza o ensino de tal gênero oral tampouco se reconhece que ele não é fruto de convivências cotidianas.

Desta forma, o seminário serve apenas para ensinar literatura e não há qualquer preocupação com a reelaboração do texto oral, ou seja, se o aluno fizer uma apresentação insatisfatória, não terá a oportunidade de rever suas fragilidades e melhorar sua produção oral.

Fonte: As Autoras (2017). 
Assim, a oralidade presente nos materiais é reducionista e na maioria das situações aparece a serviço da escrita. Por exemplo, no "Caderno do Aluno", volume 2, da 3a série, na Situação de Aprendizagem 1: Trabalho Infantil: Interessa a quem? (p. 5), deparamo-nos com a presença da oralidade em forma de discussão oral entre os colegas da classe sobre algumas perguntas selecionadas. Porém, essa discussão oral aparece para levantar conhecimentos prévios que favorecerão uma produção textual escrita, que é apresenta no final da Situação de Aprendizagem (p. 12) com a proposta de atividade: produção de um texto dissertativo. É interessante notarmos que nos referidos materiais existem sondagens, estudos linguísticos, oferta de ampliação de repertórios e proposta de reescrita para gêneros textuais escritos como o artigo de opinião, a resenha etc. Fica explícita a constatação de que a língua escrita é mais valorizada nos materiais do que a aprendizagem dos gêneros orais secundários.

\section{CONSIDERAÇÕES FINAIS}

Considerando a oralidade como uma modalidade de utilização da língua e considerando a diversidade de textos orais formais que são utilizados nas interações sociais, torna-se essencial a valorização do ensino de gêneros orais secundários nas escolas de Ensino Médio, visto que tais gêneros são essenciais à vida estudantil, mas vão além dos muros da escola, colaborando para que o aluno tenha possibilidade de prosseguir os estudos, seja preparado para o mercado de trabalho e exerça sua cidadania.

Contudo, as atividades analisadas nos materiais didáticos "Caderno do Professor" e "Caderno do Aluno" mostram que existe oralidade em quase todas as situações propostas, mas não há o ensino sistematizado de gêneros textuais orais secundários. Considerando o procedimento genebrino da Sequência Didática como uma abordagem metodológica organizada em etapas para ensinar o domínio de um gênero textual, notamos que há sistematização de aulas para aprendizagem de gêneros escritos, porém não se destaca preocupação semelhante com gêneros orais.

Em linhas gerais, o planejamento textual não privilegia as características dos textos orais. $\mathrm{A}$ elaboração inicial do texto acontece sem 0 levantamento das dificuldades dos alunos para intervenção docente, fato este que minimiza as atividades de análise linguística. E as situações didáticas que trabalham com entrevistas e seminários não chegam à produção final, entendida como um processo de reelaboração do texto.

Sendo assim, a oralidade está espalhada ao longo do material, sob a forma de conversas entre alunos e professor, contudo falta sistematização para o ensino da elaboração de gêneros orais secundários e para a compreensão da oralidade formal nas práticas sociais. Os materiais, portanto, não favorecem o ensino da oralidade, pois não a enfatizam.

Desse modo, é essencial a intervenção docente, cabe ao professor engajar o uso da oralidade cada vez mais no seu projeto de ensino, ampliando ou construindo atividades com a oralidade para os alunos de Ensino Médio, até que os materiais didáticos analisados sejam revistos e melhorados pelo sistema de ensino no que se refere ao tema desta pesquisa.

\section{REFERÊNCIAS}

BAKHTIN, M. Os gêneros do discurso. In: Bakhtin, M. Estética da criação verbal. São Paulo: Martins Fontes, 2003. p. 261-306.

CURADO, O. H. F. Linguagem e dialogismo. In: CECCANTINI, J. L. C. T. et al. (org.). Pedagogia cidadã: cadernos de formação: língua portuguesa. São Paulo: UNESP, Pró-Reitoria de Graduação, 2004. p. 19-26.

DOLZ, J.; NOVERRAZ, M.; SCHNEUWLY, B. Sequências didáticas para o oral e a escrita: apresentação de um procedimento. In: DOLZ, Joaquim; SCHNEUWLY, Bernard. (org). Gêneros orais e escritos na escola. Campinas: Mercado de Letras, 2004. p. 95-128.

GATINHO, J. B. M. Sequências de atividades didáticas propostas por professores em formação continuada. In: SIGNORINI, Inês (Org.). Gêneros catalisadores: letramento e formação docente. São Paulo: Parábola, 2006. p. 143-156.

GERALDI, J. W. O texto na sala de aula: leitura e produção. São Paulo: Ática, 2011.

MARCONI, M. A.; LAKATOS, E. M. Fundamentos de metodologia científica. 5. ed. São Paulo: Atlas, 2003. 
SÃO PAULO (ESTADO). Secretaria da Educação. Caderno do Aluno: língua portuguesa, $1^{a}$ série do ensino médio. São Paulo, 2014a. v. 1 -2.

SÃO PAULO (ESTADO). Caderno do Aluno: língua portuguesa, 2a série do ensino médio. São Paulo, 2014b. v. $1-2$.

SÃO PAULO (ESTADO). Caderno do Aluno: língua portuguesa, 3a série do ensino médio. São Paulo, 2014c. v. $1-2$.

SÃO PAULO (ESTADO). Caderno do Professor: língua portuguesa, 1a série do ensino médio. São Paulo, 2014d. v. 1 -2.

SÃO PAULO (ESTADO). Caderno do Professor: língua portuguesa, 2a série do ensino médio. São Paulo, 2014e. v. 1 -2.

SÃO PAULO (ESTADO). Caderno do Professor: língua portuguesa, 3a série do ensino médio. São Paulo, 2014f. v. 1 -2.

SÃO PAULO (ESTADO). Currículo do Estado de São Paulo: linguagens, códigos e suas tecnologias; coordenação geral, Maria Inês Fini; coordenação de área, Alice Vieira. 2. ed. São Paulo, 2012.

SOARES, M. Letramento: um tema em três gêneros. 2.ed. Belo Horizonte: Autêntica, 2004.

Recebido para publicação em: 02/10/2017

Revisado em: 09/11/2017

Aceito em: 17/01/2018 